\title{
Development and Power Calculation of a Grinding Wheel Design for Ultra-High-Speed Grinding
}

\author{
Denis Rechenko ${ }^{1, *}$, Renat Kamenov ${ }^{1}$ \\ ${ }^{1}$ Omsk State Technical University, RU-644050, Omsk, Russia
}

\begin{abstract}
Increasing the structural reliability at ultra-high-speed grinding is an important problem because it defines safety of metalworking. The purpose of work is to achieve the cutting speed up to $400-500 \mathrm{~m} / \mathrm{s}$ by developing a new design of the grinding wheel with the possibility of u sing different g rinding materials. Grinding wheel design for ultra-high-speed grinding was developed based on calculations carried out using the tear design method, which allows determining the maximum possible circumferential speed, and finite element method used to determine the equivalent stresses, plastic deformations, circumferential and radial movements. The possibility of development of a grinding wheel design for ultra-high-speed grinding has been tested experimentally. The developed designs of grinding wheels show may poddibly be used on super high-speed $t$ echnological eq uipment $f$ or processing of pa $\mathrm{rts} \mathrm{m}$ ade $\mathrm{o} f$ ha rd-to-machine $\mathrm{m}$ aterials. Calculations and comprehensive experimental tests of the de sign of g rinding wheels for $u$ ltra-high-speed grinding c arried pit in this w ork a llow de termining the serviceability and the maximum pos sible cutting speed and provide useful information for the further development of grinding tools.
\end{abstract}

\section{Introduction}

An a nalysis of the existing d esigns of $g$ rinding wheels for $\mathrm{h}$ igh-speed gr inding $\mathrm{s}$ hows $\mathrm{t}$ hat $\mathrm{t}$ he maximum circumferential machining speed of up to $160 \mathrm{~m} / \mathrm{s}$ can be achieved (Table 1). Standard g rinding wheels for highspeed grinding have a strength that allows processing at speeds up to $60-160 \mathrm{~m} / \mathrm{s}$ [1-17]. After refining the existing designs, it is possible to reach cutting speeds of about $250 \mathrm{~m} / \mathrm{s}$ i n 1 aboratory c onditions without a ny possibility o $f$ further i ndustrial a pplications o $\mathrm{ft}$ he refined design. In the case, when the cutting speed limit is ex ceeded, the i ndividual components ar e t orn off or the grinding wheel housing is torn apart. There exist the following criteria for the grinding wheel design:

- the grinding wheel can run at the highest possible cutting speed without risk of rupture;

- the ability to use different grinding materials;

- simplicity of design w ith a m inimum num ber of stress concentrators;

- reliability o $\mathrm{ft}$ he $\mathrm{c}$ lamping $\mathrm{d}$ esign o $\mathrm{fgr}$ inding segment.

Table 1. Grinding wheel designs.

\begin{tabular}{|l|l|l|c|}
\hline № & Sketch & Strength & $\begin{array}{c}\text { Description of } \\
\text { how to increase } \\
\text { the strength of a } \\
\text { grinding wheel } \\
\text { structure }\end{array}$ \\
\hline
\end{tabular}

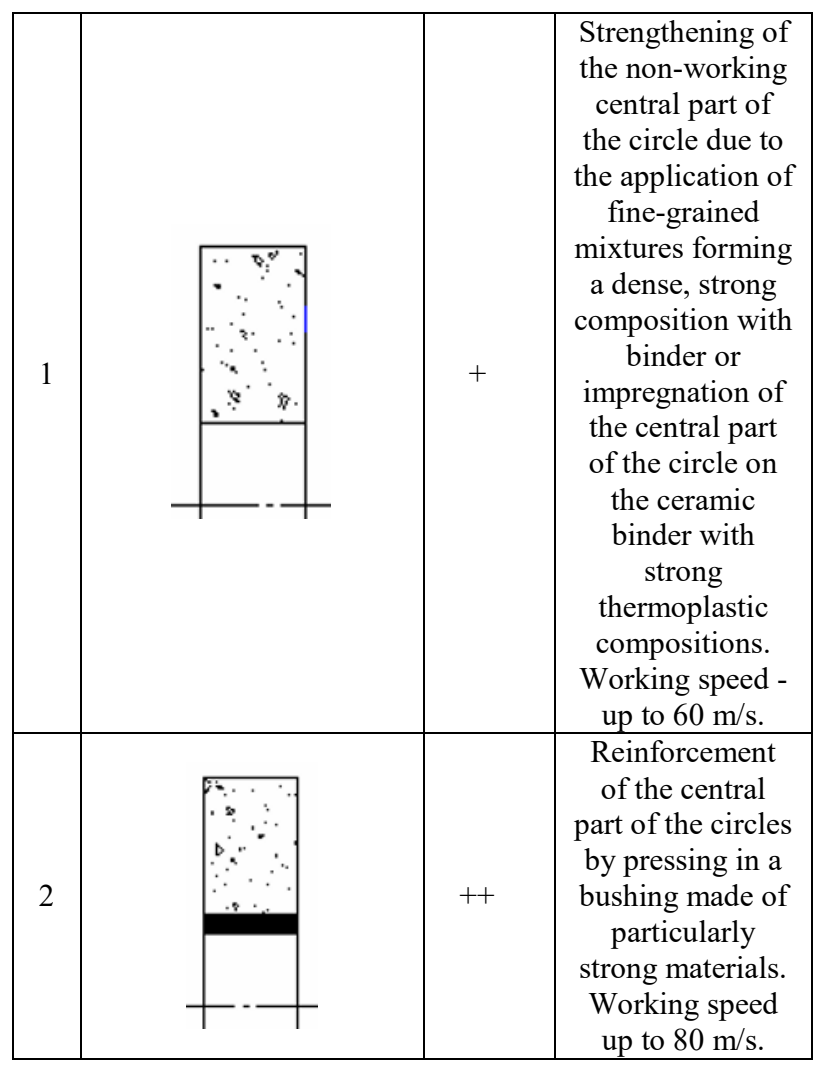

*Corresponding author: rechenko-denis@mail.ru 


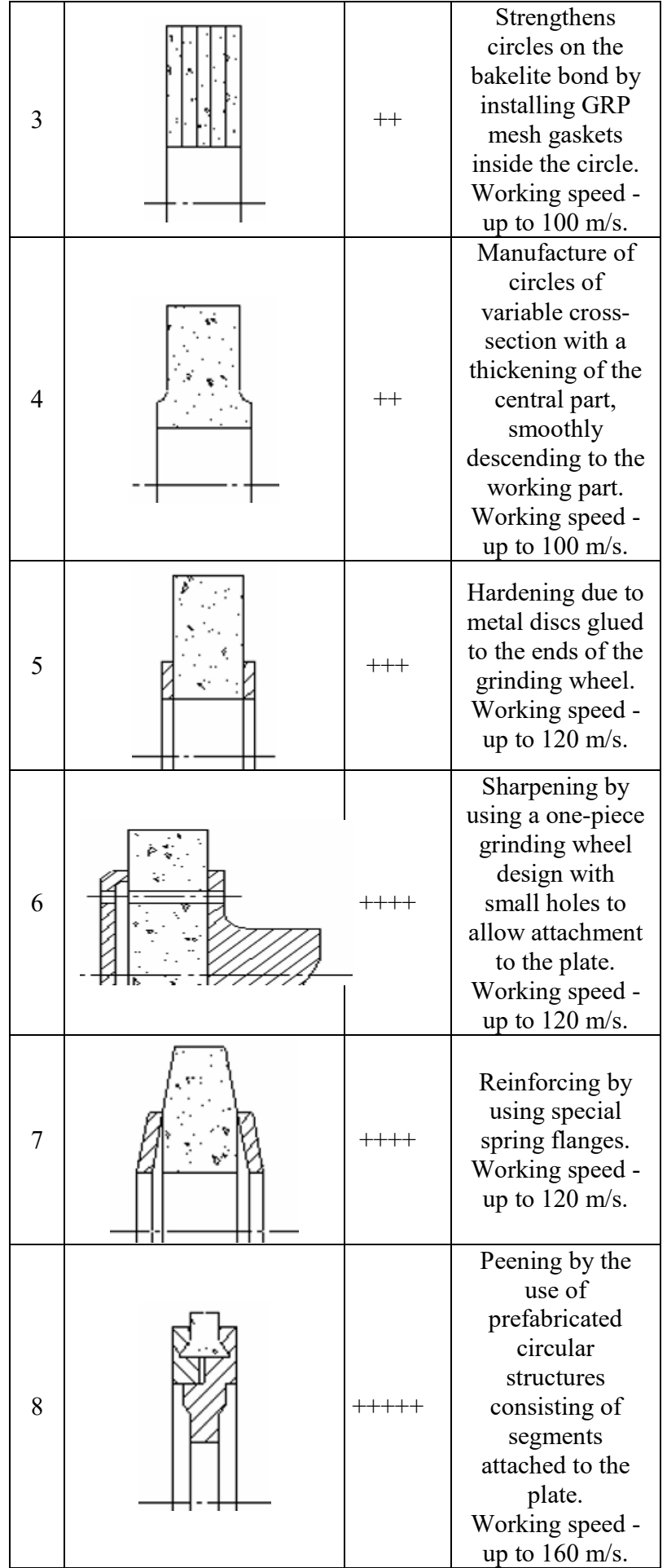

Creating a new design that allows for safe grinding at the highest possible circumferential speed is a complex task that requires a car eful consideration of the strength, maximum pos sible ope rating $s$ peeds, $t$ he system of attachment of the grinding elements and fixing the body in the spindle shaft.

Some designs of grinding wheels include the use of metal bandages, shroud, etc., which significantly reduces the possibility of their rupture. The analysis of the existing designs has been shown that a grinding wheel for $u$ ltra-high-speed $\mathrm{p}$ rocessing $\mathrm{n}$ eeds an a ll-metal cas $\mathrm{e}$ with $\mathrm{t}$ he $\mathrm{s}$ mallest $\mathrm{n}$ umber o $\mathrm{f} \mathrm{p}$ arts an $\mathrm{d} t$ hat $\mathrm{t}$ he $\mathrm{s}$ afety margin factor should be 1.4 (GOST R 52857.1-2007).

\section{Problem statement}

Cutting speeds of up to $400-500 \mathrm{~m} / \mathrm{s}$ can be achieved by designing a ne $\mathrm{w}$ grinding wheel $\mathrm{d}$ esign with $\mathrm{t}$ he possibility o $\mathrm{fu}$ sing $\mathrm{d}$ ifferent $\mathrm{g}$ rinding materials. Grinding wheel design for ultra-high-speed grinding was calculated using the tear design method, which allows to determine the maximum possible ci rcumferential s peed and finite el ement method t $\mathrm{o} d$ etermine $t$ he eq uivalent stresses, plastic deformations, circumferential and radial movements in the process.

\section{Analysis and development of bindings of grinding segment}

Development of replaceable grinding segments, namely the $\mathrm{c}$ ircuit a nd $\mathrm{t}$ he mechanism of $\mathrm{t}$ heir fixation is a $\mathrm{n}$ important $t a s k, b$ ecause $t$ he performance of $t$ he e ntire process unit d epends o $\mathrm{n}$ it. Different grinding s egment characteristics can only be implemented with a one-piece grinding wheel ho using with mounting s ockets $f$ or replacement segments. Studies of aerodynamic work have shown that the most appropriate use of cylindrical grinding segments. From possible schemes of fastening of grinding segments, the author offers and considers the most technological and having a simple design (Fig. 1) [2-7].

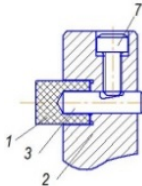

a)

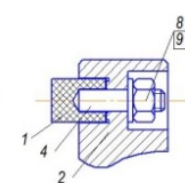

b)

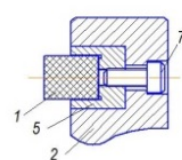

C)

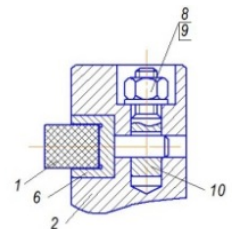

d)
1 - grinding h ead; 2 - body of g rinding w heel; 3 - oblique groove pi n; 4 - threaded pin; 5 - beaker; 6 - beaker on pin; 7 - fastening bolt; 8 - fastening nut; 9 - washer; 10 - trunnion block

Fig. 1. Fastening structures for replacement grinding segments: a) fastening with a radial bolt; b) fastening with an axial nut; c) fastening with an axial bolt; d) fastening with a radial nut.

The pr esented de signs of $\mathrm{f}$ astening of grinding segments provide reliable fastening, thus fastening with a radial bolt (Fig. 1, a) provides simplicity of realization of $t$ his de sign on the ba sis of $s$ tandard g rinding h eads with a pin. The use of the attachment structure with an axial nut (Fig. 1, b) is quite dangerous, as the attachment force a lso works on de taching the di amond head from the $\mathrm{p}$ in. The use of axial bolt fixing (Fig. 1.c) seems to be th e $m$ ost $r$ ational, $d$ ue to th e $s$ implicity o $f$ it $s$ construction and the c lamping force being provided exclusively on the bucket in which the grinding segment is located. The design of the attachment with a radial nut (Fig. 1.d) i s r eliable, bu $\mathrm{t} \mathrm{c}$ omplex i n e xecution a nd operation.

The $\mathrm{r}$ esults o fs trength $\mathrm{c}$ alculations o f va rious abrasive and binder materials are shown in Figure 2, the shear $\mathrm{s}$ tress $\mathrm{d}$ ependence on $\mathrm{t}$ he grinding wheel circumferential speed is presented. 


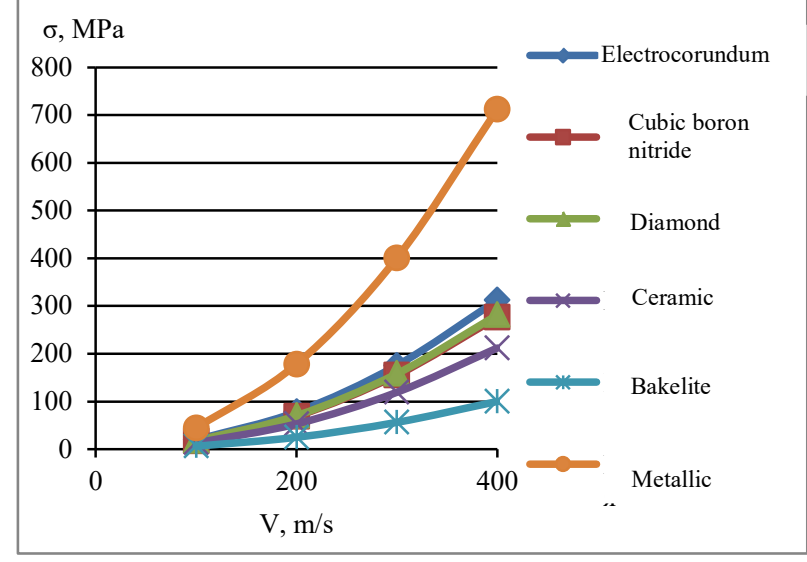

Fig. 2. Cut $\mathrm{v}$ oltage de pendence o $\mathrm{ng}$ rinding $\mathrm{w}$ heel circumferential speed.

It can be seen from the dependence that the bakelite ligament has shear stresses at a seed of $400 \mathrm{~m} / \mathrm{s}$ ab out $100 \mathrm{MPa}$. Standard grinding inserts have a strength limit of about $30-40 \mathrm{MPa}$, so it is necessary to develop grinding i nserts o $\mathrm{nt}$ he $\mathrm{b}$ akelite binder, providing the ability to work at speeds up to $400 \mathrm{~m} / \mathrm{s}$, while ensuring the appropriate shear strength.

According $\mathrm{t}$ o $\mathrm{t}$ he $\mathrm{c}$ onducted $\mathrm{t}$ ests, $\mathrm{t}$ he be nding strength limit $\mathrm{f}$ or $\mathrm{t}$ he gi ven d eveloped formulations is 120.2...153.8 M Pa, w hich pr ovides t he c oefficient of safety margin in the range of 1.2-1.5.

The nu mber of $g$ rinding s egments is de termined by the heat $d$ issipation $c$ ondition $d$ uring gr inding a nd the effective $\mathrm{p}$ ower $\mathrm{c}$ ondition. When $\mathrm{c}$ alculating the different number of heads involved $\mathrm{i} n \mathrm{gr}$ inding, $\mathrm{t}$ he working ar ea must be determined. The working surface area of the diamond heads is 4 pcs., is $8 \%-S_{\text {heads }}=1257$ $\mathrm{mm}^{2}$ and $S_{\text {work }}=15708 \mathrm{~mm}^{2}$. Accordingly, at $16 \mathrm{pc} \mathrm{s}$. $S_{\text {work }}=62832 \mathrm{~mm}^{2}$.

\section{Determining the maximum permissible grinding wheel speed for high-speed machining}

Grinding wheel calculation comes down to de termining the maximum permissible cutting speed at which a grinding wheel is capable of machining. The maximum circumferential speed of the grinding wheel is influenced by the b ody material, $d$ imensions a nd $\mathrm{s}$ hape. The calculation i $\mathrm{s}$ car ried $\mathrm{o}$ ut $\mathrm{f}$ or $\mathrm{t}$ hree $\mathrm{p}$ roposed $\mathrm{s}$ eating options: nozzle, striking face and end face (Fig. 3), based on the allowable tension on the tension of the material of the body of the circle [8-15].

Grinding wheels for rupture are calculated according to the allowable stress and the stress arising from centrifugal forces from the condition:

$$
\sigma \leq[\sigma]
$$

where $\sigma$ - tensile stress arising during operation due to centrifugal forces, $\mathrm{MPa} ;[\sigma]$ - permissible tensile stress, $\mathrm{MPa}$.

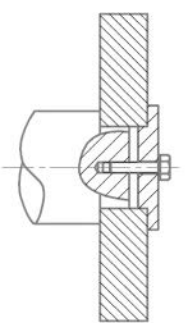

a)

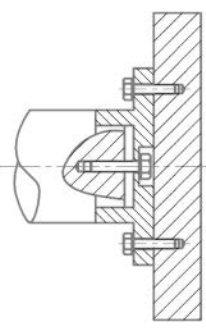

b)

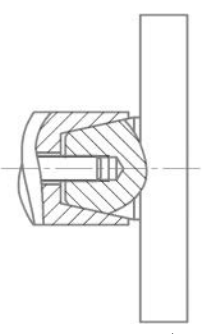

c)
Fig. 3. Fitting o ptions $\mathrm{f}$ or a $\mathrm{n} \mathrm{u}$ ltra-fast $\mathrm{g}$ rinding $\mathrm{w}$ heel: a) nozzle mount; b) striking mount; c) end mount.

The cal culation o $\mathrm{ft}$ ensile $\mathrm{s}$ tresses $\mathrm{i} \mathrm{s} b$ ased o $\mathrm{n}$ formulas:

$$
\begin{aligned}
& \text { - for a disk }-\sigma=\frac{\rho \cdot V_{r}^{2}}{2} \\
& \text {-for a ring- } \sigma=\frac{R \cdot \rho \cdot V_{r}^{2}}{R-r},
\end{aligned}
$$

where $\rho$ - ringing wheel body material density, $\mathrm{kg} / \mathrm{m}^{3}$; $V_{r}$ - linear grinding wheel speed at the calculated radius, $\mathrm{m} / \mathrm{s} ; R$ - calculated grinding wheel radius, $\mathrm{m} ; r$ - landing radius, $m$.

Based on the expressions (1,2 and 3 ), the maximum allowed ci rcumferential $\mathrm{s}$ peed $\mathrm{i} \mathrm{s}$ cal culated $\mathrm{b}$ y the formulas:

$$
\begin{gathered}
- \text { for a disk }-V_{r}=\sqrt{\frac{2 \cdot[\sigma]}{\rho}} ; \\
- \text { for a ring }-V_{r}=\sqrt{\frac{(R-r) \cdot[\sigma]}{\rho \cdot R}} .
\end{gathered}
$$

Figure 4 a nd T able 2 show the r esults of ho using calculations for $\mathrm{d}$ ifferent materials. O verall $\mathrm{d}$ imensions $R=125 \mathrm{~mm} ; r=38 \mathrm{~mm}$.

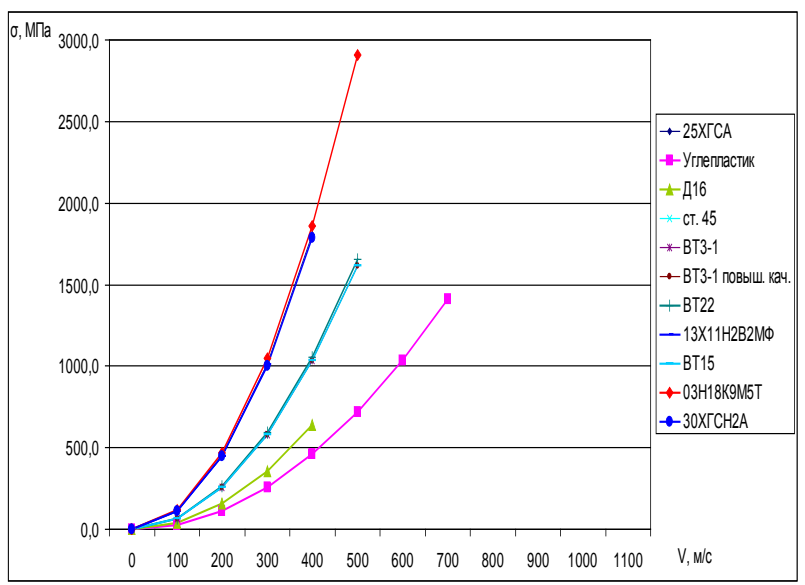

Fig. 4. Dependence o $\mathrm{ft}$ ensile $\mathrm{s}$ tress o $\mathrm{n} t$ he ci rcumferential speed of the grinding wheel in different materials.

Application of 30KhGSN2A or VT3-1 of the raised quality as the case of a grinding wheel allows to receive break rates to 667,8 and $720,2 \mathrm{~m} / \mathrm{s}$ a ccordingly. Taking into acco unt $\mathrm{t}$ he $\mathrm{s}$ afety factor o $\mathrm{f} 1.4 \mathrm{w}$ e will $\mathrm{g}$ et $\mathrm{t}$ he maximum c utting speed of 484.2 a nd $543.0 \mathrm{~m} / \mathrm{s}$ respectively. 
Table 2. Grinding wheel body calculation results from different materials.

\begin{tabular}{|c|c|c|c|c|c|c|c|}
\hline \multirow[t]{2}{*}{ № } & \multirow[t]{2}{*}{$\begin{array}{l}\text { Grinding } \\
\text { wheel } \\
\text { body } \\
\text { material }\end{array}$} & \multirow[t]{2}{*}{ 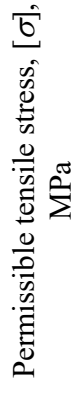 } & \multirow[t]{2}{*}{ 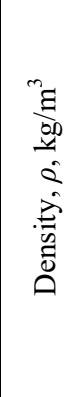 } & \multicolumn{2}{|c|}{$\begin{array}{l}\text { Maximum } \\
\text { allowable } \\
\text { linear break } \\
\text { rate, } V_{r}, \mathrm{~m} / \mathrm{s}\end{array}$} & \multicolumn{2}{|c|}{$\begin{array}{c}\text { Maximum } \\
\text { permissible } \\
\text { operating } \\
\text { speed with } \\
\text { safety } \\
\text { factor in } \\
\text { mind, } V_{r}, \\
\mathrm{~m} / \mathrm{s}\end{array}$} \\
\hline & & & & $a$ & \begin{tabular}{l|l}
$b$ & $c$
\end{tabular} & $a$ & \begin{tabular}{l|l}
$b$ & $c$
\end{tabular} \\
\hline 1. & AlCu4Mg1 & 460 & 2770 & 576,6 & 340,0 & 411,6 & 242,8 \\
\hline 2. & C45 & 600 & 7800 & 392,2 & 231,4 & 280,2 & 165,3 \\
\hline 3. & $\begin{array}{l}\text { 13Kh11N2 } \\
\text { VMF-Sh }\end{array}$ & 950 & 7800 & 493,5 & 291,2 & 352,5 & 208,0 \\
\hline 4. & 25KhGSA & 1080 & 7850 & 524,6 & 309,4 & 374,7 & 221,0 \\
\hline 5. & VT3-1 & 1180 & 4500 & 724,2 & 379,3 & 517,3 & 270,9 \\
\hline 6. & VT22 & 1280 & 4620 & 746,0 & 440,1 & 532,9 & 314,3 \\
\hline 7. & VT15 & 1500 & 4500 & 816,5 & 481,7 & 583,2 & 344,0 \\
\hline 8. & $\begin{array}{l}\text { 30KhGSN } \\
\text { 2A }\end{array}$ & 1620 & 7770 & 645,7 & 380,9 & 461,2 & 272,1 \\
\hline 9. & $\begin{array}{l}\text { 03H18K9 } \\
\text { M5T }\end{array}$ & 1920 & 8050 & 688,5 & 406,2 & 491,8 & 290,1 \\
\hline
\end{tabular}

Titanium alloy VT3-1 i s of hi gher q uality $\mathrm{i} n$ comparison with other materials and existing structures due $\mathrm{t} o$ its lower d ensity a nd h igh te nsile strength. However, du e t o i ts de nsity a nd c orrespondingly the final weight of the grinding wheel, the use of this material is li mited b y its $v$ ibration $r$ esistance, $i$. e. th $\mathrm{e}$ design does not have sufficient vibration resistance. Therefore, $\mathrm{t}$ he material 3 OKhGSN2A cap able of providing $t$ he $r$ equired $\mathrm{c}$ utting $\mathrm{s}$ peeds a $\mathrm{t} v$ ibration disturbances was used [16-17].

\section{Experimental results and discussion. Grinding wheel load and stress analysis}

Calculation a nd $\mathrm{d}$ istribution o $\mathrm{f} s$ tresses in a $\mathrm{g}$ rinding wheel was made by a method of finite el ements with application o $\mathrm{fc}$ alculation a nd a nalytical $\mathrm{p}$ rogram ANSYS. The work presents the calculations of strength, static strength, e lastic a nd e lastic $\mathrm{p}$ lastic $\mathrm{c}$ alculations. The a uthor $\mathrm{c}$ onsiders $\mathrm{t}$ wo $\mathrm{v}$ ariants o f a rrangement of machining elements: horizontally and at an angle of 45 degrees a nd of fers de signs ( figure 5 a nd 6). The ar bor and spindle are also calculated.

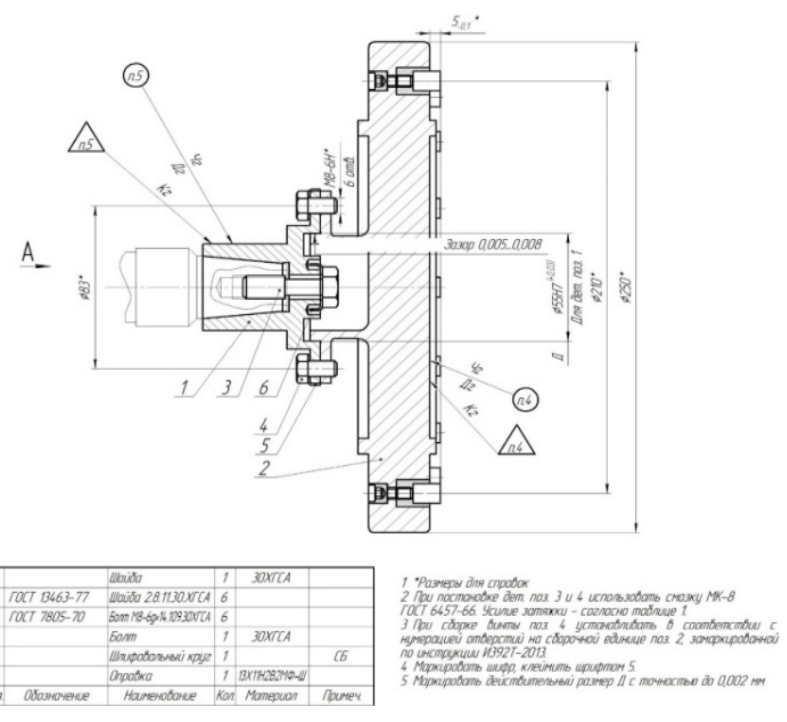

Fig. 5. Grinding wheel for ul tra-fast g rinding with hor izontal machining units

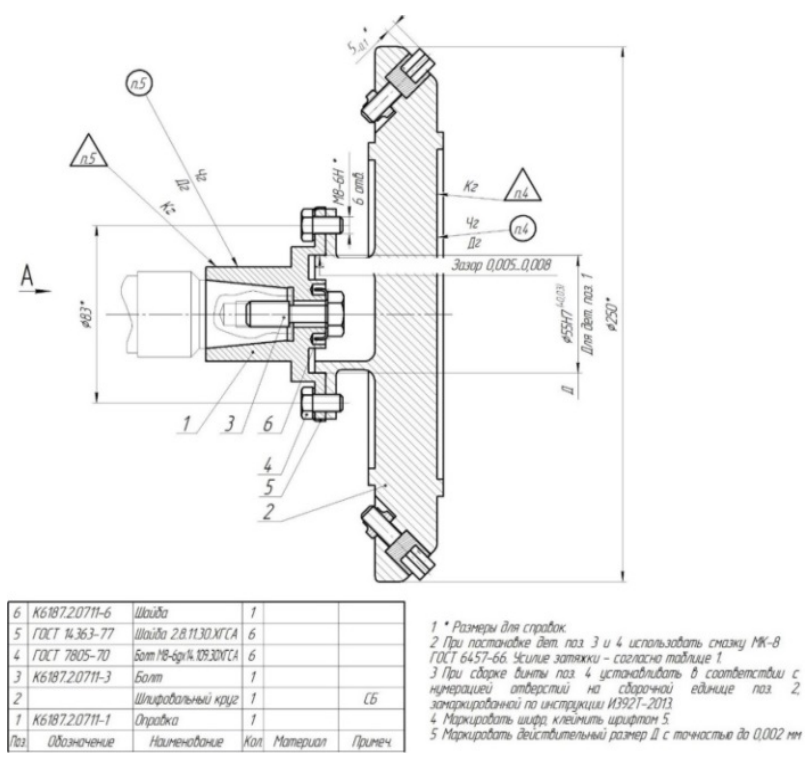

Fig. 6. Grinding wheel for ul tra-fast g rinding with 45 de gree grinding angles

The de veloped $\mathrm{h}$ igh-speed $\mathrm{g}$ rinding and $\mathrm{g}$ rinding wheel has the following main parameters:

1) maximum circle diameter up to $250 \mathrm{~mm}$;

2) maximum width up to $40 \mathrm{~mm}$;

3) maximum working speed up to $400 \mathrm{~m} / \mathrm{s}$;

4) number of machining elements - 16 pieces;

5) two arrangement options for the machining elements.

The $\mathrm{g}$ rinding wheel $\mathrm{c}$ onsists of $\mathrm{t}$ he bod $\mathrm{y}$ a nd $\mathrm{t}$ he machining elements. Body material - 13Kh11N2V2MFSh $\left(\sigma_{0,2}=950 \mathrm{M} \mathrm{Pa}\right)$. P roperties of the material: $E=$ $196200 \mathrm{MPa}\left(20000 \mathrm{kgf} / \mathrm{mm}^{2}\right)$ - modulus of elasticity; $\mu$ $=0,3-$ Poisson's ratio; $\sigma_{v}=1100 \mathrm{MPa}$ - tensile strength; $\sigma_{0,2}=950 \mathrm{MPa}$ - yield strength; $\delta=1,5 \%$ - percentage elongation; $H=1360 \mathrm{MPa}$ - hardening module; $\rho=7,8$ $\mathrm{g} / \mathrm{sm}^{3}$ - density.

The w eight calculation of $\mathrm{t}$ he gr inding he ads is shown i n T able 3 . W ith ho rizontal a rrangement $M=$ 21,718 g, with 45-degree machining position $M=29,663$ g. 
Table 3. Grinding head weight calculation.

\begin{tabular}{|c|c|c|c|c|c|c|c|c|}
\hline \multirow{2}{*}{$\begin{array}{c}\text { Loc } \\
\text { atio } \\
\text { n } \\
\text { hea } \\
\text { d }\end{array}$} & \multirow[b]{2}{*}{$\begin{array}{c}\text { De } \\
\text { tail } \\
\mathrm{s}\end{array}$} & \multirow[b]{2}{*}{ Material } & \multirow{2}{*}{$\begin{array}{c}\begin{array}{c}\text { De } \\
\text { nsit }\end{array} \\
\text { y } \\
\rho, \\
\mathrm{g} / \mathrm{s} \\
\mathrm{m}^{3}\end{array}$} & \multirow[b]{2}{*}{$\begin{array}{c}D, \\
\mathrm{~mm}\end{array}$} & \multicolumn{2}{|c|}{$\begin{array}{c}\text { Dimens } \\
\text { ions }\end{array}$} & \multirow{2}{*}{$\begin{array}{c}\begin{array}{c}\text { Volu } \\
\text { me }\end{array} \\
\begin{array}{c}V, \\
\mathrm{~mm}^{3}\end{array}\end{array}$} & \multirow{2}{*}{$\begin{array}{c}\begin{array}{c}\text { Mas } \\
\mathrm{s}\end{array} \\
M, \mathrm{~g}\end{array}$} \\
\hline & & & & & $\begin{array}{l}d, \\
\mathrm{~m} \\
\mathrm{~m}\end{array}$ & $\begin{array}{l}L, \\
\mathrm{~m} \\
\mathrm{~m}\end{array}$ & & \\
\hline \multirow{11}{*}{ 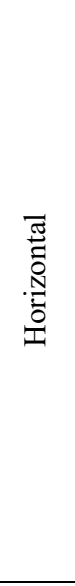 } & $\begin{array}{l}\overrightarrow{8} \\
\text { ஜ }\end{array}$ & Abrasive & 4,15 & 10 & 3 & 13 & 929,13 & 3,856 \\
\hline & \multirow{4}{*}{ 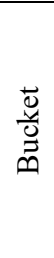 } & \multirow{4}{*}{$\mathrm{C} 45$} & 7,8 & 14 & 10 & 8 & 603,19 & 4,705 \\
\hline & & & 7,8 & 14 & 6 & $\begin{array}{l}5 \\
9\end{array}$ & 741,42 & 5,783 \\
\hline & & & 7,8 & 9 & 0 & $\begin{array}{c}2, \\
1\end{array}$ & 133,6 & 1,042 \\
\hline & & & 7,8 & 9 & 5 & $\begin{array}{c}2, \\
1\end{array}$ & 94,5 & 0,737 \\
\hline & \multirow{5}{*}{\begin{tabular}{l}
3 \\
\multirow{0}{0}{} \\
0
\end{tabular}} & \multirow{5}{*}{$\begin{array}{c}13 \mathrm{Kh} 11 \\
\text { N2V2M } \\
\text { F-Sh } 1\end{array}$} & 7,8 & 6 & 0 & 8 & 226,19 & 1,764 \\
\hline & & & 7,8 & 4,5 & 0 & 4 & 63,617 & 0,496 \\
\hline & & & 7,8 & 10 & 0 & 9 & 706,86 & 5,513 \\
\hline & & & 7,8 & 8,4 & 0 & 3 & $-166,3$ & $-1,297$ \\
\hline & & & 7,8 & 6 & 0 & 4 & $-113,1$ & $-0,882$ \\
\hline & & & & & & & & 21,718 \\
\hline \multirow{9}{*}{ 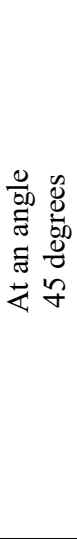 } & 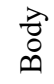 & Abrasive & 4,15 & 10 & 3 & 13 & 929,13 & 3,856 \\
\hline & \multirow{5}{*}{ 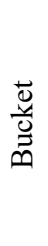 } & \multirow{5}{*}{$\mathrm{C} 45$} & 7,8 & 14 & 10 & 8 & 603,19 & 4,705 \\
\hline & & & 7,8 & 14 & 0 & 6 & 923,63 & 7,204 \\
\hline & & & 7,8 & 9 & 0 & 2 & 127,23 & 0,992 \\
\hline & & & 7,8 & 9 & 5 & 2 & 90 & 0,702 \\
\hline & & & 7,8 & 8 & 0 & 20 & 1005,3 & 7,841 \\
\hline & \multirow{2}{*}{ 咅 } & & 7,8 & 14 & 8 & $\begin{array}{c}4, \\
5\end{array}$ & 466,53 & 3,639 \\
\hline & & & 7,8 & 9,5 & 8 & $\begin{array}{c}4, \\
5\end{array}$ & 92,775 & 0,724 \\
\hline & & & & & & & & 29,663 \\
\hline
\end{tabular}

Centrifugal force of grinding he ads with horizontal arrangement $\mathrm{C}=30156 \mathrm{~N}$ (3074 kgf), with an angle of 45 degrees $\mathrm{C}=32108 \mathrm{~N}$ (3273 kgf).

\section{Housing with horizontal grinding heads}

The volume solid model of the grinding wheel body is built. A sector ( $1 / 6 \mathrm{part}$ ) is cut out of the body. This sector i s t aken as a cal culation model. $\mathrm{T}$ he $\mathrm{c}$ yclosymmetric model is fixed along the axis of rotation and in the circumferential direction[18-20].

Elements in the form of a t etrahedron ar e $u$ sed $t \mathrm{o}$ generate a finite element grid. The sector is divided into $\mathrm{NEL}=1796237 \mathrm{f}$ inite e lements a nd c ontains $\mathrm{K} \mathrm{N}=$ 316998 nodes. Calculation of the stress-strain state (SSS) of the wheel is made from the act ion of cen trifugal forces o ccurring in the body, an d from the cen trifugal forces of grinding heads $\mathrm{C}=30156 \mathrm{~N} \quad(3074 \mathrm{k} \mathrm{gf})$. Operating s peed $n=34725 \mathrm{~min}^{-1}(\omega=3636 \mathrm{r}$ ad/s $)$. Figures $7-9 \mathrm{~s}$ how $\mathrm{t}$ he $\mathrm{r}$ esults of $\mathrm{t}$ he ca se S SS u nder working conditions. The greatest stresses are in the grinding head holes and are local in nature. Equivalent voltages in them $\sigma_{e}{ }^{\max }=942 \mathrm{M} \mathrm{Pa}$. Equivalent $\mathrm{p}$ lastic deformation in the holes $\varepsilon_{p}=0,035 \%$. Voltages in the astragal molding of the car rier $\mathrm{p}$ in $\mathrm{f}$ abric $875 \mathrm{M} \mathrm{Pa}$. Voltages in the hub $803 \mathrm{MPa}$.

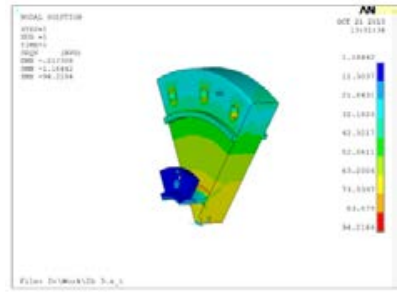

a)

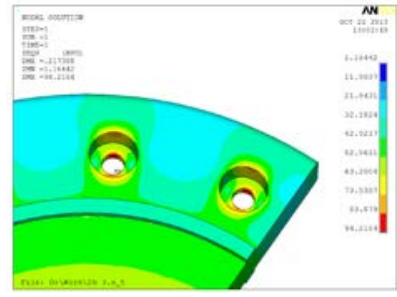

b)
Fig. 7. Equivalent stresses in sector (a) and grinding head holes (b).

Radial movements:

flange holes (83 $\mathrm{mm}$ diameter) $\mathrm{UR}=0.0163 \mathrm{~mm}$; holes for grinding heads ( $105 \mathrm{~mm}$ diameter) $\mathrm{UR}=0.184$ $\mathrm{mm}$.

Axial movements ho les for grinding he ads o $\mathrm{n} t$ he abrasive side ( $105 \mathrm{~mm}$ diameter) $\mathrm{UZ}=0.065 \mathrm{~mm}$. The housing i s e venly s tretched o ut i $\mathrm{n} r$ adial direction a nd narrowed in axial direction.

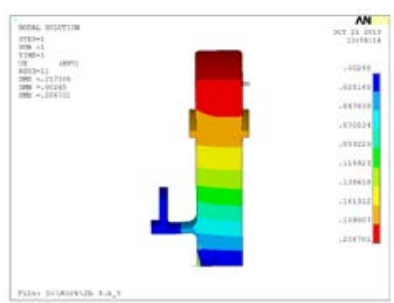

a)

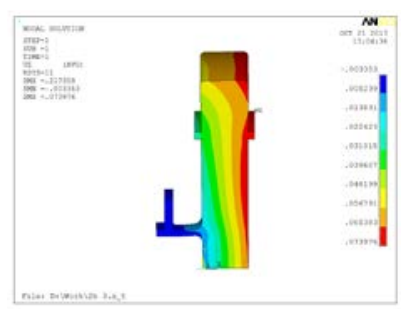

b)
Fig. 8. Radial movements (a) and axial movements (b).

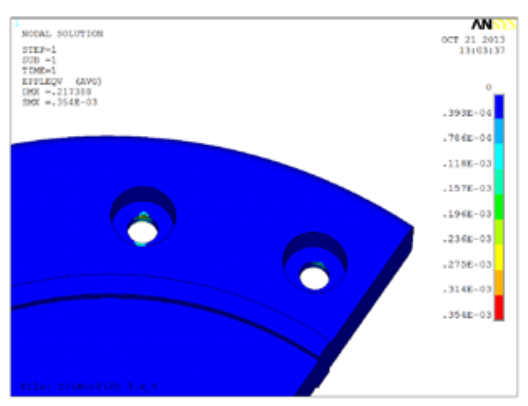

Fig. 9. Equivalent plastic deformation.

When cal culated acco rding t o t he t wo-dimensional scheme of the stress $s$ tate with $\mathrm{s}$ tress a veraging on the thickness of the disk, the safety margin $\mathrm{Km}=1.651$ in the cen ter o $\mathrm{ft}$ he $\mathrm{d}$ isk. Allowance $\mathrm{f}$ or $\mathrm{d}$ estructive rotational speed $\mathrm{Kv}=1.425$. Stocks are sufficient.

\section{Enclosure with angled grinding heads}

The volume solid model of the grinding wheel body is built. A sector (1/16 part) is cut out of the body. This sector i s t aken as a cal culation model. The c yclosymmetric model is fixed along the axis of rotation and in the circumferential direction.

Elements in the form of a $\mathrm{t}$ etrahedron are $\mathrm{u}$ sed $\mathrm{t} \mathrm{o}$ generate a finite element grid. The sector is divided into $\mathrm{NEL}=898532$ finite elements and contains $\mathrm{KN}=$ 160671 node. Calculation of the stress-strain state (SSS) of $\mathrm{t}$ he wheel i s made from $\mathrm{t}$ he act ion o f cen trifugal forces arising in the body and from the centrifugal forces of $\mathrm{g}$ rinding h eads $\mathrm{C}=32108 \mathrm{~N}$ ( $3273 \mathrm{kgf}$ ). Operating 
speed $n=30558 \mathrm{~min}^{-1}(\omega=3200 \mathrm{rad} / \mathrm{s})$. Figures 1 0-12 show the SSS on the hull under working conditions

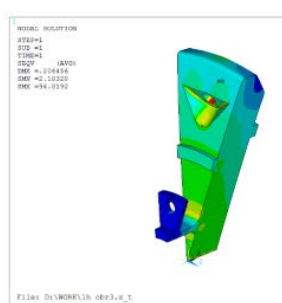

a)

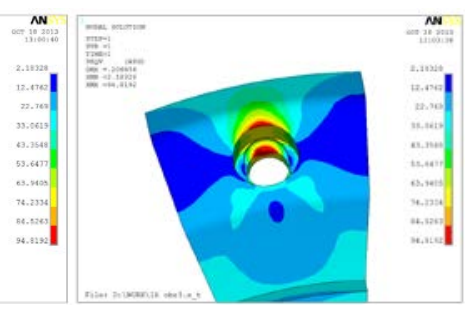

b)
Fig. 10. Equivalent tensions in sector (a) and into the grinding head opening (b).

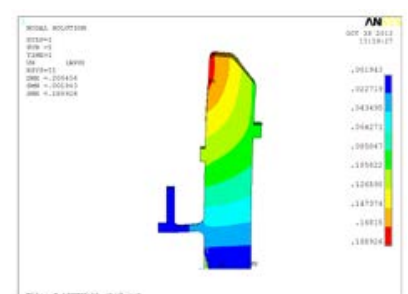

a)

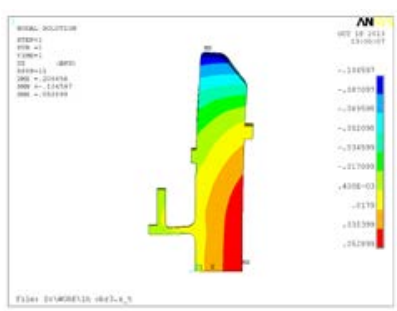

b)
Fig. 11. Radial movements (a) and axial movements (b).

The greatest $\mathrm{s}$ tresses are in the grinding head holes and ar e 1 ocal i $\mathrm{n} n$ ature. Equivalent voltages i $\mathrm{nt}$ hem $\sigma_{e k q}{ }^{\max }=948 \mathrm{MPa}$. Equivalent plastic deformation in the holes $\varepsilon_{p}=0,3 \%$. Voltages in the astragal molding of the carrier $\mathrm{p}$ in f abric $722 \mathrm{MP}$ a. V oltages in the hub 604 $\mathrm{MPa}$.

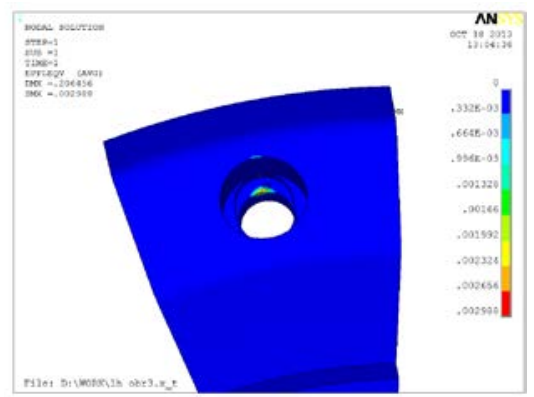

Fig. 12. Equivalent plastic deformation

Radial movements:

flange bores ( $83 \mathrm{~mm}$ diameter) $U_{R}=0,0137 \mathrm{~mm}$; grinding head bores on the abrasive side $(105 \mathrm{~mm}$ diameter) $U_{R}=0,127 \mathrm{~mm}$.

Axial movements:

grinding head holes on the abrasive side (105 mm diameter) $U_{Z}=0,07 \mathrm{~mm}$.

The body in the central part is evenly stretched out radially and narrowed axially. The periphery of the casing $b$ ends $t$ o t he abrasive $s$ ide. When cal culated according to the $\mathrm{t}$ wo-dimensional $\mathrm{s}$ cheme of $\mathrm{t}$ he stress state with stress a veraging on the thickness of the disk, the safety margin $\mathrm{Km}=2.132$ in the center of the disk. Inventory at destructive speed $\mathrm{Kv}=1.619$.

\section{Calculating mandrel and spindle}

In o rder $t o$ as sess the failure $t$ o o pen $t$ he joint between the s pindle and mandrel, cal culations of these elements from the action of centrifugal forces were made. Figures 13 a nd $14 \mathrm{~s}$ how the e quivalent $\mathrm{s}$ tresses and radial mo vements. At the points of contact between the spindle and mandrel, the mandrel displacement is 3 $\mu \mathrm{m}$, while the s pindle $\mathrm{d}$ isplacement is $0.5 \mu \mathrm{m}$. This results in a conicity of $1: 5$ to the axial displacement of the mandrel by $\delta=(3-0.5) \cdot 5 \cdot 2=25 \mu \mathrm{m}$.

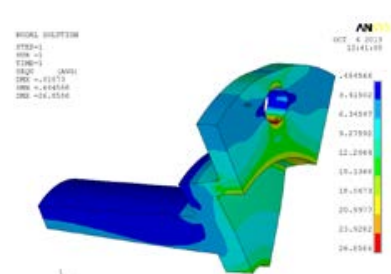

a)

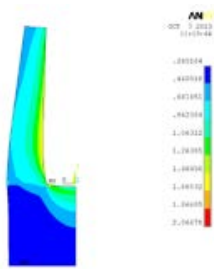

b)
Fig. 13. Equivalent stresses in mandrel (a) and spindle (b).

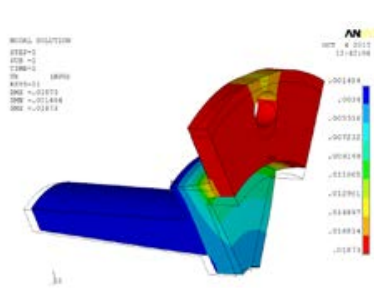

a)
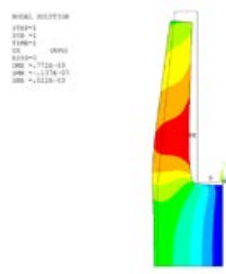

b)
Fig. 14. Radial movements in mandrel (a) and spindle (b).

This movement causes the tightening to be loosened. For this reason, a s pecial flow screw has been designed to compensate for axial movement.

Radial displacement o f flange bores $(83 \mathrm{~mm}$ diameter) $U_{R}=0.017 \mathrm{~m} \mathrm{~m}$, a lmost id entical to th $\mathrm{e}$ movements of the housing flange.

\section{Conclusion}

This work leads us to the following conclusions:

1. T he s trength of hi gh-speed gr inding wheels has been cal culated. $T$ wo $v$ ariants o $f$ ar rangement o $f$ machining el ements ar e co nsidered: h orizontally an $\mathrm{d}$ at an an gle of $45 \mathrm{~d}$ egrees. The ho rizontal version of the grinding heads $\mathrm{i} \mathrm{sp}$ referable. The cas ing $\mathrm{d}$ eforms uniformly without bending. Manufacturing this casing is less time-consuming.

2. The mandrel and spindle are calculated. According to calculations, a special screw with a flow was designed to co mpensate $\mathrm{t}$ he a xial movement o $\mathrm{ft}$ he mandrel relative to the spindle.

3. Radial movements in the area of the flange holes ( $83 \mathrm{~m} \mathrm{~m}$ i $\mathrm{n} \mathrm{d}$ iameter) a $\mathrm{t} t$ he ho using a nd mandrel a re nearly the same.

\section{Acknowledgments}

The work was carried out with the financial support of the $\mathrm{G}$ rant $\mathrm{C}$ ouncil of the President o $\mathrm{ft}$ he $\mathrm{R}$ ussian Federation for s tate support of young Russian s cientists and for state support of leading scientific schools of the Russian Federation, grant number MD-345.2020.8. 


\section{References}

1. M.M. Paley, Grinding and grinding technology of the cutting tool / M.M. Paley, L.G. Dibner, M.D. Flyd (M.: Mashinostroenie, 1988)

2. Pat. 101666 Russian Federation, MPK B 24 D 7/06. Grinding $\mathrm{w}$ heel $\mathrm{f}$ or high-speed $\mathrm{m}$ achining / D.S. Rechenko, K.V. Averkov, A.Yu. Popov; applicant an do wner o fO mGTU - № 2010139548/02; de clared. 24. 09.2010; o p. 27.01.2011, Bulletin No. 3. - 2 c.: silt.

3. Pat. 146505 R ussian F ederation, I PC B 24D 3/32. Grinding to ol / D.S. Rechenko, B.P. Kudryashov, A.Yu. Popov; applicant and owner of OmGTU - № 2014123264/02; de clared.06. 06.2014; o p. 10.10.2014, Bulletin No. 28. - 1 c.: silt.

4. Pat. 2440229 Russian Federation, IPC B 24B 1/00, B24B 9/ 16, B 28D 5/ 02. Method of s uperhard materials $\mathrm{p}$ rocessing / D.S. Rechenko, A.Yu. Popov. 08.02.2010; op. 20.01.2012, Bulletin No. 2. -1 c.

5. Pat. 2547980 Russian F ederation, IPC B 24B 3/36. Method of sharpening the metal-cutting tool blade with a gr inding wheel/ D.S. Rechenko, A.Yu. Popov; applicant and owner of OmGTU - № 2013142129/02; de clared. 13. 09.2013; op. 10.04.2015, Bulletin No. 10. - 1 c.

6. Pat. 55665 Russian Federation, MPK B24D 17/00. Grinding wheelf or di amond a nd a brasive machining / D.S. Rechenko, Yu.R. Nurtdinov, A.Yu. Popov; applicant and owner of OmGTU - № 2006111080/22; de clared. 05.04.2006; o p. c it. 27.08.2006, Bulletin No. 24. - 2 p.: silt.

7. D.S. Rechenko, Improvement of quality of the highspeed sharpening of the carbide tools by the diamond circles with the interrupted surface: (Dissertation ... Cand. of Sciences, Tomsk, 2009)

8. V.A. Rybitskiy, S ynthetic diamonds., 3, 32-35 (1978)

9. L.N. Filimonov, High-speed grinding / L.N. Filimonov. - L.N (Filimonov: $\mathrm{M}$ ashinostroenie, Leningr. departing, 1979)

10. L.N. Filimonov, Grinding wheel resistance / L.N. Filimonov. - L.N (Filimonov: $\mathrm{M}$ ashinostroenie, 1973)

11. D.S. R echenko, A .G. K ol'tsov, Russian Engineering Research, 32(2), 179 - 181 (2012)

12. D.S. Rechenko, A.Y. Popov, K.V. Averkov, V.A. Sergeev, Russian Engineering Research, 32(56), $511-512(2012)$

13. L. T ian, Y . F ub, J . X ub, H . Li , W . D ing, International $\mathrm{J}$ ournal o $\mathrm{f}$ Machine $\mathrm{T}$ ools \& Manufacture, 89, 192-201 (2015)

14. C. $\mathrm{W}$ ang, Q. F ang, J . C hen, Y . Li u, T . J in, International $\mathrm{J}$ ournal of Advanced $\mathrm{M}$ anufacturing Technology, 83, 937-948 (2016)

15. L. Y ang, Y . F u, J . X u, Y . Liu, M aterials a nd Design, 88, 827-836 (2015)
16. Z. Zhao, Z. Fu, J. Xu, Z. Zhang, The International Journal of Advanced $M$ anufacturing $\mathrm{T}$ echnology, 87, 3545-3555 (2016)

17. Y. Zhu, W. Lu, Y. Sun, D. Zuo, The International Journal of Advanced M anufacturing T echnology, 89, 1269-1277 (2017)

18. S.N. Grigoriev, V.A. Grechishnikov, M.A. Volosova, X . Jiang, P .M. Pivkin, In IOP Conference $S$ eries: $M$ aterials $S$ cience a nd Engineering, 971(2), $022065 \quad$ (2020) doi: 10.1088/1757-899X/971/2/022065

19. S.N. Grigoriev, P.M. Pivkin, V.A. Grechishnikov, Y.E. Petukhov, M .A. Volosova, A.B. Nadykto, Emerging I maging a nd $\mathrm{S}$ ensing $\mathrm{T}$ echnologies for Securitya nd D efence $\mathrm{V}$; an $\mathrm{d} A$ dvanced Manufacturing Technologies for Micro-and Nanosystems in S ecurity a nd D efence I II, 11540, 115401E (2020) https://doi.org/10.1117/12.2574389

20. S.N. Grigoriev, M.A. Volosova, A. A. Okunkova, S.V. Fedorov, K. Hamdy, P .A. Podrabinnik, ..., A.N. Porvatov, J. Manuf. Mater. Process., 4(3), 96 (2020) https://doi.org/10.3390/jmmp4030096 